\title{
Front Matter: Volume 9275
}

, "Front Matter: Volume 9275," Proc. SPIE 9275, Infrared, Millimeter-Wave, and Terahertz Technologies III, 927501 (13 December 2014); doi:

$10.1117 / 12.2181061$

SPIE. Event: SPIE/COS Photonics Asia, 2014, Beijing, China 


\title{
PROCEEDINGS OF SPIE
}

\section{Infrared, Millimeter-Wave, and Terahertz Technologies III}

\author{
Cunlin Zhang \\ Xi-Cheng Zhang \\ Masahiko Tani \\ Editors \\ 9-10 October 2014 \\ Beijing, China \\ Sponsored by \\ SPIE \\ COS-Chinese Optical Society

\section{Cooperating Organizations}

Tsinghua University (China) • Peking University (China) • University of Science and Technology of China (China) • Zhejiang University (China) - Tianjin University (China) • Beijing Institute of Technology (China) • Beijing University of Posts and Telecommunications (China) • Nankai University (China) • Changchun University of Science and Technology (China) • University of Shanghai for Science and Technology (China) • Capital Normal University (China) • Huazhong University of Science and Technology (China) • Beijing Jiaotong University (China) • Shanghai Institute of Optics and Fine Mechanics (China) • Changchun Institute of Optics and Fine Mechanics (China) - Institute of Semiconductors (China) - Institute of Optics and Electronics (China) • Institute of Physics (China) • Shanghai Institute of Technical Physics (China) • China Instrument and Control Society (China) - Optoelectronics Technology Committee, COS (China) • SPIE National Committee in China (China) - Optical Society of Japan (Japan) • Optical Society of Korea (Korea, Republic of) - The Australian Optical Society (Australia) - Optics and Photonics Society of Singapore (Singapore) • European Optical Society

Supporting Organizations

CAST_China Association for Science and Technology (China)

NSFC-National Nature Science Foundation (China)

Published by

SPIE

Volume 9275

Proceedings of SPIE 0277-786X, V. 9275

SPIE is an international society advancing an interdisciplinary approach to the science and application of light.

Infrared, Millimeter-Wave, and Terahertz Technologies III, edited by Cunlin Zhang, Xi-Cheng Zhang, Masahiko Tani, Proc. of SPIE Vol. 9275, 927501 - @ 2014 SPIE · CCC code: 0277-786X/14/\$18 · doi: 10.1117/12.2181061 
The papers included in this volume were part of the technical conference cited on the cover and title page. Papers were selected and subject to review by the editors and conference program committee. Some conference presentations may not be available for publication. The papers published in these proceedings reflect the work and thoughts of the authors and are published herein as submitted. The publisher is not responsible for the validity of the information or for any outcomes resulting from reliance thereon.

Please use the following format to cite material from this book:

Author(s), "Title of Paper," in Infrared, Millimeter-Wave, and Terahertz Technologies III, edited by Cunlin Zhang, Xi-Cheng Zhang, Masahiko Tani, Proceedings of SPIE Vol. 9275 (SPIE, Bellingham, WA, 2014) Article CID Number.

ISSN: 0277-786X

ISBN: 9781628413489

Published by

SPIE

P.O. Box 10, Bellingham, Washington 98227-0010 USA

Telephone +1 3606763290 (Pacific Time) · Fax +1 3606471445

SPIE.org

Copyright (c) 2014, Society of Photo-Optical Instrumentation Engineers.

Copying of material in this book for internal or personal use, or for the internal or personal use of specific clients, beyond the fair use provisions granted by the U.S. Copyright Law is authorized by SPIE subject to payment of copying fees. The Transactional Reporting Service base fee for this volume is $\$ 18.00$ per article (or portion thereof), which should be paid directly to the Copyright Clearance Center (CCC), 222 Rosewood Drive, Danvers, MA 01923. Payment may also be made electronically through CCC Online at copyright.com. Other copying for republication, resale, advertising or promotion, or any form of systematic or multiple reproduction of any material in this book is prohibited except with permission in writing from the publisher. The CCC fee code is 0277-786X/14/\$18.00.

Printed in the United States of America.

Publication of record for individual papers is online in the SPIE Digital Library.

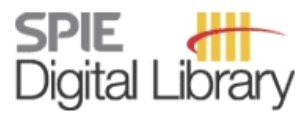

SPIEDigitalLibrary.org

Paper Numbering: Proceedings of SPIE follow an e-First publication model, with papers published first online and then in print and on CD-ROM. Papers are published as they are submitted and meet publication criteria. A unique, consistent, permanent citation identifier (CID) number is assigned to each article at the time of the first publication. Utilization of CIDs allows articles to be fully citable as soon as they are published online, and connects the same identifier to all online, print, and electronic versions of the publication. SPIE uses a six-digit CID article numbering system in which:

- The first four digits correspond to the SPIE volume number.

- The last two digits indicate publication order within the volume using a Base 36 numbering system employing both numerals and letters. These two-number sets start with 00, 01, 02, 03, $04,05,06,07,08,09,0 A, 0 B \ldots 0 Z$, followed by 10-1Z, 20-2Z, etc.

The CID number appears on each page of the manuscript. The complete citation is used on the first page, and an abbreviated version on subsequent pages. Numbers in the index correspond to the last two digits of the six-digit CID number. 


\title{
Contents
}

\author{
vii Authors \\ ix Symposium Committees \\ xi Conference Committee
}

SESSION 1 TERAHERTZ SENSING AND APPLICATION I

$927505 \quad$ Effect on influenza hemagglutinin protein binding with neutralizing antibody using terahertz spectroscopy technology [9275-3]

927506 Terahertz isolator in metal plate waveguide [9275-4]

927507 Tailoring fabrication parameters of silver helical metamaterials for enhanced polarization properties in terahertz regime [9275-5]

\section{SESSION 2 TERAHERTZ SENSING AND APPLICATION II}

$92750 \mathrm{~A} \quad$ Conductively coupled resonator scheme for dispersive transparency in metamaterials (Invited Paper) [9275-8]

9275 OB Terahertz properties of metallic checkerboard patterns and related structures [9275-9]

9275 OC Terahertz gas sensing based on high Q one-dimensional photonic crystal cavity [9275-10]

9275 OD Low-frequency vibration study of amino acids using terahertz spectroscopy and solid-state density functional theory [9275-11]

\section{SESSION 3 TERAHERTZ GENERATION AND DETECTION}

9275 OE THz wave generation from micro-plasma (Invited Paper) [9275-12]

\section{SESSION 4 TERAHERTZ TECHNOLOGIES AND APPLICATION}

9275 0J Processing sequence for non-destructive inspection based on 3D terahertz images (Invited Paper) [9275-17]

9275 OK Fabrication of broadband antireflection coating at terahertz frequency using a hot emboss method (Invited Paper) [9275-18]

$9275 \mathrm{OL}$ Terahertz polarization conversion of metallic meanderline structures on the different thickness of polymide substrates [9275-19] 
$92750 \mathrm{M}$ A new architecture of high dynamic range readout circuits for IR FPA [9275-20]

SESSION 5 INFRARED, MILLIMETER-WAVE, AND TERAHERTZ TECHNOLOGIES AND APPLICATION

9275 OT A $20 \mathrm{MHz} 15 \mu \mathrm{m}$ pitch $128 \times 128$ CTIA ROIC for InGaAs focal plane array [9275-25]

9275 OU Infrared image segmentation method based on spatial coherence histogram and maximum entropy [9275-26]

9275 OV Design of the small pixel pitch ROIC [9275-27]

\section{POSTER SESSION}

9275 OX Research on the infrared image processing algorithm based on FPGA [9275-29]

$92750 Z$ Far-field beam-pattern of a twin-slot HEB mixer at 600GHz (Best Student Paper Award) [9275-31]

927510 2D reconstruction of terahertz Gabor inline digital holography [9275-32]

927511 Simulated annealing method for material parameter extraction with terahertz time-domain spectroscopy [9275-33]

927514 A W-band subharmonic Schottky mixer for millimeter imaging [9275-36]

927515 Frequency spectrum of a THz QCL in pulse mode measured by an FTS system [9275-37]

927517 Personnel screening with terahertz opto-mechanical scanning imaging [9275-39]

927518 Design of a ROIC with high dynamic range for LWIR FPAs [9275-40]

927519 High efficiency coupler for terahertz anti-resonate waveguide [9275-41]

$92751 \mathrm{~A} \quad$ Identification of polypeptides by using SOM neural networks [9275-42]

9275 1B Applications of Bruggeman effective medium theory in mixture using terahertz spectrum [9275-43]

9275 1D Influence of incident wave polarization on the transmission properties of terahertz metamaterials [9275-45]

$9275 \mathrm{lE} \quad$ Multi-heterodyne molecular absorption spectrum detection of $\mathrm{H}^{3} \mathrm{C}^{14} \mathrm{~N}$ based on dual frequency combs [9275-46]

9275 1G Experimental methods of indoor millimeter-wave radiometric imaging for personnel concealed contraband detection [9275-48]

$927511 \quad$ Extracting accurate complex refractive index from solid pellets based on time-domain terahertz reflection spectroscopy [9275-50] 
$92751 \mathrm{~J}$ Studies on spectroscopy of glycerol in THz range using microfluidic chip-integrated micropump [9275-51]

$92751 \mathrm{~K} \quad$ Target recognition in passive terahertz image of human body [9275-52]

$9275 \mathrm{lL}$ Terahertz spectra of glycerol, water, and their mixture in a microfluidic chip [9275-53]

$92751 \mathrm{~N} \quad$ A single-frame terahertz image super-resolution reconstruction method based on sparse representation theory [9275-55]

927510 A polarization-independent terahertz modulator based on metamaterials with symmetric structure [9275-56]

$9275 \mathrm{IP}$ Orbit angular momentum encoding at $0.3 \mathrm{THz}$ via 3D printed spiral phase plates [9275-60]

$92751 Q \quad$ Terahertz imaging system based on bessel beams via 3D printed axicons at $100 \mathrm{GHz}$ [9275-59]

9275 IR Understanding the high order cavity modes in parallel plate waveguide with single deep groove [9275-61] 
Proc. of SPIE Vol. $9275927501-6$

Downloaded From: https://www.spiedigitallibrary.org/conference-proceedings-of-spie on 26 Apr 2023 Terms of Use: https://www.spiedigitallibrary.org/terms-of-use 


\title{
Authors
}

Numbers in the index correspond to the last two digits of the six-digit citation identifier (CID) article numbering system used in Proceedings of SPIE. The first four digits reflect the volume number. Base 36 numbering is employed for the last two digits and indicates the order of articles within the volume. Numbers start with 00, 01, 02, 03, 04, 05, 06, 07, 08, 09, OA, OB...0Z, followed by 10-1Z, 20-2Z, etc.

\author{
Akalin, Tahsin, $\mathrm{OB}$ \\ Balacey, H., OJ \\ Banas, Agnieszka, OA \\ Banas, Krzysztof, OA \\ Bettiol, Andrew A., 07, OA \\ Bou Sleiman, J., OJ \\ Buccheri, F., OE \\ Cai, Bin, OK, IR \\ Chahadih, Abdallah, $\mathrm{OB}$ \\ Chang, Sheng-Jiang, 06 \\ Chen, Honglei, OV \\ Chen, Lin, 1R \\ Chen, Sai, 06 \\ Chen, Tao, OC \\ Chen, Tianji, 19 \\ Chen, Yu, OT \\ Choi, Kwan Bum, 07 \\ Cui, Hailin, 10 \\ Dai, Yao, OU \\ Dauplay, Frederic, $\mathrm{OZ}$ \\ Delorme, Yan, $\mathrm{OZ}$ \\ Deng, Chao, 17 \\ Deng, Chao, 1K, 1N \\ Ding, Qing, 14 \\ Ding, Ruijun, OM, OV, 18 \\ Fan, Fei, 06 \\ Fang, Jiaxiong, ОТ \\ Feng, Lishuang, 1D \\ Feret, Alexandre, $\mathrm{OZ}$ \\ Gao, Lei, OV \\ Ghaddar, Abbas, OB \\ Gu, Chang, OL \\ Guan, Yonghe, 11 \\ Guillet, J.-P., OJ \\ Guo, Lan-tao, 17 \\ Han, Xiang-Lei, $\mathrm{OB}$ \\ Han, Xue, $1 \mathrm{~J}, 1 \mathrm{~L}$ \\ Han, Zhanghua, $O C$ \\ Hangyo, Masanori, OB \\ Hayashi, Michitoshi, OD \\ $\mathrm{He}$, Jingsuo, 10 \\ He, Ting, 19, $1 \mathrm{~A}$ \\ $\mathrm{He}$, Yingfeng, 11 \\ Hong, Zhi, OC \\ Hu, Jia-Qi, 10 \\ $\mathrm{Hu}, \mathrm{Jie}, 14$ \\ Hu, Taiyang, $1 \mathrm{G}$ \\ Huang, Ruirui, OL \\ Huang, Songlei, OT
}

\author{
Huang, Xiaoyuan, 11 \\ Huang, Zhangcheng, OT \\ Jia, Qiongzhen, 11 \\ Jiang, Dazhao, OM, OV \\ Jiao, Lei, 10 \\ Kou, Kuan, OL \\ Lefevre, Roland, $0 Z$ \\ Li, Chenlong, 1D \\ Li, Hao, $1 \mathrm{G}$ \\ Li, Qi, 10 \\ Li, Shao-Liang, 15 \\ Li, Yan, $1 \mathrm{E}$ \\ Li, Yue, 1K, 1N \\ Li, Yun-Da, 10 \\ Li, YunZhou, OK \\ Liang, Qinghua, OM, OV \\ Lin, Zhen-Hui, 15 \\ Ling, Dongxiong, 11 \\ Liu, Changming, IP, $1 Q$ \\ Liu, Jianjun , OC \\ Liu, Jianwei, IA \\ Liu, Jinsong, $1 \mathrm{P}, 1 \mathrm{Q}$ \\ Liu, Songtao, OU \\ Liv, Xin, 17 \\ Lou, Zheng, 0Z, 14 \\ LU, Xuan, $1 G$ \\ LV, Rongchuan, $1 \mathrm{G}$ \\ Miao, Wei, 15 \\ Miyamaru, Fumiaki, $\mathrm{OB}$ \\ Mounaix, P., OJ \\ Okui, Yuichiro, OB \\ Padilla, Willie J, OB \\ Perraud, J.-B., OJ \\ Recur, B., OJ \\ Shen, Jingling, 19, 1A \\ Shen, Tongsheng, OU \\ Shi, Sheng-Cai, OZ, 14, 15 \\ Song, Qiang, IR \\ Su, Bo, 1J, $1 \mathrm{~L}$ \\ Sun, Ping, 11 \\ Sun, Yiwen, 05 \\ Takano, Keisuke, OB \\ Tanaka, Yoku, OB \\ Tominaga, Keisuke, OD \\ Turaga, Shuvan Prashant, 07, 0A \\ Vacelet, Thibaut, $\mathrm{OZ}$ \\ Vaurette, François, $\mathrm{OB}$ \\ Wang, Hongcheng, 11 \\ Wang, Houng-Wei, OD
}


Wang, Jian, $1 \mathrm{P}$

Wang, Kejia, 1P, 1Q

Wei, Haoyun, $1 E$

Wei, Xuli, 1P, 1Q

Wu, Jianfeng, OA

Wu, Ying, $1 \mathrm{~J}, 1 \mathrm{~L}$

Xiao, Zelong, $1 \mathrm{G}$

Xin, Li, OX

Yan, Yuanjun, 07

Yang, Honglei, $1 \mathrm{E}$

Yang, Qinghua, 11

Yang, Zhenggang, 1P, 1Q

Yao, Qij-Jun, 15

Zhai, Yongcheng, 0V, 18

Zhang, Bo, 19, 1A

Zhang, Cheng-Jiang, 14

Zhang, Cun-lin, 05, 17, 1B, 1J, 1K, 1L, 1N, 10

Zhang, Feng, OD

Zhang, Leiwei, 1B

Zhang, Lin, 1l

Zhang, X.-C., OE

Zhang, $Y u, 11$

Zhang, Zhongqi, IP, 1Q

Zhao, Guozhong, OL

Zhao, Ran, $1 \mathrm{~K}$

Zhao, Yong-Peng, 10

Zhao, Yuan-meng, 17, 1K, 1N

Zhong, Junlan, 05

Zhou, Kang-Min, $\mathrm{OZ}$

Zhou, Zhen, 1D

Zhu, Long, IP

Zhu, YiMing, OK, IR

Zou, Yun, 11

Zuo, Jian, 05, 1B 


\title{
Symposium Committees
}

\author{
General Chairs
}

H. Philip Stahl, NASA Marshall Space Flight Center (USA)

Bingkun Zhou, Tsinghua University (China)

General Co-chairs

Arthur Chiou, National Yang-Ming University (Taiwan, China)

Jianlin Cao, China Ministry of Science and Technology (China)

Junhao Chu, Shanghai Institute of Technical Physics (China)

Technical Program Chairs

Songlin Zhuang, Shanghai University of Science and Technology (China)

Xingde Li, Johns Hopkins University (United States)

Technical Program Co-chairs

Qiming Wang, Institute of Semiconductors (China)

Xu Liu, Zhejiang University (China)

Daoyin Yu, Tianjin University (China)

Qihuang Gong, Peking University (China)

Tianchu Li, National Institute of Metrology (China)

Wei Huang, Nanjing University of Posts and Telecommunications (China)

Local Organizing Committee Chair

Guangcan Guo, University of Science and Technology of China (China) 
Local Organizing Committee Co-chairs

Guoqiang Ni, Beijing Institute of Technology (China)

Shusen Xie, Fujian Normal University (China)

Xiaomin Ren, Beijing University of Posts and Telecommunications (China)

Ying Gu, People's Liberation Army General Hospital (China)

Huilin Jiang, Changchun University of Science and Technology (China)

General Secretary

Qihuang Gong, Peking University (China)

Local Organizing Committee

Yan Li, Chinese Optical Society/Peking University (China)

Zhiping Zhou, Peking University (China)

Changhe Zhou, Shanghai Institute of Optics and Fine Mechanics (China)

Qingming Luo, Huazhong University of Science and Technology (China)

Chongxiu Yu, Beijing University of Posts and Telecommunications (China)

Hongda Chen, Institute of Semiconductors (China)

Yongtian Wang, Beijing Institute of Technology (China)

Yiping Cui, Southeast University (China)

Xuping Zhang, Nanjing University (China)

Feijun Song, Daheng Corporation (China)

Cunlin Zhang, Capital Normal University (China)

Yanting Lu, Nanjing University (China)

Yuejin Zhao, Beijing Institute of Technology (China)

Chunqing Gao, Beijing Institute of Technology (China)

Tiegen Liu, Tianjin University (China)

Xiaocong Yuan, Nankai University (China)

Weimin Chen, Chongqing University (China)

Zhongwei Fan, Academy of Optoelectronics (China)

Hanyi Zhang, Tsinghua University (China)

Lan Wu, Zhejiang University (China)

Yongsheng Zhang, University of Science and Technology of China (China)

Hong Yang, Peking University (China)

Xiaoying Li, Tianjin University (China)

Wei Xiong, Chinese Optical Society (China) 


\title{
Conference Committee
}

\author{
Conference Chairs
}

Cunlin Zhang, Capital Normal University (China)

Xi-Cheng Zhang, Huazhong University of Science and Technology

(China) and University of Rochester (United States)

Masahiko Tani, University of Fukui (Japan)

\section{Conference Program Committee}

Peter A. R. Ade, Cardiff University (United Kingdom)

Yi Cai, Kunming Institute of Physics (China)

Jun-Cheng Cao, Shanghai Institute of Microsystem and Information Technology (China)

Hou-Tong Chen, The Center for Integrated Nanotechnologies

(United States)

Jian Chen, Nanjing University (China)

Yuping Cui, Tianjin Jinhang Institute of Technology Physics (China)

Jianming Dai, University of Rochester (United States)

Haewook Han, Pohang University of Science and Technology

(Korea, Republic of)

Jiaguang Han, Tianjin University (China)

Masanori Hangyo, Osaka University (Japan)

Zhi Hong, China Jiliang University (China)

Biaobing Jin, Nanjing University (China)

Weiqi Jin, Beijing Institute of Technology (China)

Sergei Ark Kozlov, National Research University of Information Technologies, Mechanics and Optics (Russian Federation)

He Li, Shanghai Institute of Technical Physics (China)

Jinsong Liu, Huazhong University of Science and Technology (China)

Chiko Otani, RIKEN (Japan)

Ci-Ling Pan, National Tsing Hua University (Taiwan, China)

Jiancheng Shi, Institute of Remote Sensing and Digital Earth (China)

Sheng-Cai Shi, Purple Mountain Observatory (China)

Alexander Pavlovich Shkurinov, Lomonosov Moscow State University (Russian Federation)

Fei-jun Song, China Daheng Group, Inc. (China)

Jianmin Yuan, National University of Defense Technology (China)

Chao Zhang, University of Wollongong (Australia)

Weili Zhang, Oklahoma State University (United States)

Yan Zhang, Capital Normal University (China)

Zhuoyong Zhang, Capital Normal University (China) 
Kun Zhao, China University of Petroleum (China)

YiMing Zhu, University of Shanghai for Science and Technology

(China)

Session Chairs

1 Terahertz Sensing and Application I

Cunlin Zhang, Capital Normal University (China)

Xi-Cheng Zhang, Huazhong University of Science and Technology

(China) and University of Rochester (United States)

2 Terahertz Sensing and Application II

Xi-Cheng Zhang, Huazhong University of Science and Technology

(China) and University of Rochester (United States)

3 Terahertz Generation and Detection

Weili Zhang, Oklahoma State University (United States)

4 Terahertz Technologies and Application

Masahiko Tani, University of Fukui (Japan)

5 Infrared, Millimeter-Wave, and Terahertz Technologies and

Application

Caihong Zhang, Nanjing University (China) 